Artículo Científico Original

$$
\text { TRÁFICO DE PESSOAS }
$$

E TRABALHO FORÇADO: UMA SINERGIA NEGATIVA

Waldimeiry Corrêa da Silva 


\section{TRÁFICO DE PESSOAS E TRABALHO FORÇADO: UMA SINERGIA NEGATIVA}

Waldimeiry Corrêa da Silva

\section{RESUMO}

O presente artigo visa discutir a sinergia negativa existente entre o Tráfico de pessoas para fins de exploração sexual e o trabalho forçado, representando uma forma manifesta de forma contemporânea de escravidão. Partimos de uma concepção humanista de salvaguarda dos direitos humanos na sociedade mediante as condições para o exercício do trabaIho digno, no qual acreditamos permitir a emancipação do indivíduo em sociedade. Diante do exposto, teremos como fundamento uma perspectiva emancipatória e crítica desde a humanização do direito internacional dos direitos humanos de modo a alcançar a proteção da dignidade humana como eixo motor dos direitos humanos. Dignidade esta que representa a possibilidade de autodeterminação do ser humano, e a potestade de ter uma vida plena, com direito à integridade física e psíquica que venha permitir a auto realização social e individual da pessoa em um marco de um estado social de direito.

Palavras chave: Tráfico de pessoas. Trabalho forçado. Forma contemporânea de escravidão. Exploração sexual. Dignidade humana.

\section{HUMAN TRAFFICKING AND FORCED LABOR: A NEGATIVE SYNERGY}

\section{ABSTRACT}

The purpose of this article is discussing the negative synergy that co-exists within human trafficking and forced labor. Our starting point is a humanist conception of the necessity of safeguarding human rights in our society through the protection of the basic conditions for a decent work that will grant the individual emancipation in society. Therefore, our foundation is grounded on an emancipatory and critic perspective that humanizes the international law of human rights in order to guarantee the active protection of human dignity, considered under this grounds the central axis of human rights. This human dignity represents the possibility of human auto-determination and the legal authority of having a full life, with the right to physical and psychical integrity allowing the auto-realization as a social and individual being in the framework of a Welfare State.

Key Words: Human trafficking; Forced labor; Contemporary slavery; Sexual exploitation; Human dignity. 


\section{Introdução}

O Tráfico de pessoas não é um fenômeno novo, possui raízes históricas no processo de escravidão e, na atualidade, estabelece conexões diretas com o crime transnacional organizado, a violência contra a mulher, trabalho forçado e a exploração sexual. Antigamente se traficava com escravos, processo que foi intensificado através do lucrativo comercio transatlântico de escravos, mediante da Convenção sobre a escravatura de 1926 tal prática recebe a condena e proibição por parte da comunidade internacional. Nesta primeira etapa de proibição do comercio de seres humanos, se determina a proibição do comércio ou mercantilização de escravos. A comunidade internacional vem trabalhando para erradicar esta prática mediante distintos normativos internacionais. Transpassando a questão racial (tráfico negreiro e de mulheres brancas) ou a questão de gênero (tráfico de mulheres), generalizando a censura a todo tipo de comercio ou mercantilização com o ser humano (Tráfico de pessoas). Entendemos que $\circ$ mencionada modalidade de tráfico fomenta e fortalece uma cultura de normalidade da escravidão como resposta aceitável para sair adiante da pobreza (provocada pelas desigualdades sociais) e a falta de aceso aos recursos básicos de milhões de mulheres e crianças, convertendo-lhe em uma "massa humana" vulnerável (não tendo seus direitos respeitados) ao domínio e a exploração. Neste contexto podemos observar o poder do comercio internacional do sexo que se fundamenta na mercantilização do corpo humano como um bem para ser explorado, comprado e vendido sem consenso do proprietário (CACHO, 2012, p.19).

O Tráfico de pessoas tem como finalidade distintas formas de exploração. Para - presente artigo teremos como escopo uma análise da sinergia negativa entre a exploração sexual e o trabalho forçado.
Para esse fim, examinaremos a situação de trabalho forçado no tráfico de mulheres para fins de exploração sexual, tendo a devida consideração de observar a existência de seus elementos constitutivos. De modo a observar a existência de aludidas práticas e, com vistas a ter presente à importância da claridade conceitual, temos consciência das complexas diferenças de caráter histórico, fático, jurídico, social e econômico entre o trabalho forçado, o Tráfico de Pessoas e outras práticas análogas à escravidão. No contexto do Tráfico de pessoas coincidimos com a ideia de Molina para quem a exploração sexual é a vitimização sexual de uma pessoa ligada a uma remuneração econômica ou outro tipo de benefício e regalias entre a vítima, o explorador e os intermediários. O corpo da pessoa explorada se utiliza como mercadoria para proveito econômico do explorador e prazer do usuário - denominado cliente ou "prostituidor" -. (MOLINA, 2008, p. 27)

Usamos metodologicamente 0 enfoque dos direitos humanos para determinar os conceitos estabelecidos pelos normativos internacionais para o tráfico de pessoas e trabalho forçado. Neste sentido, recorremos a uma análise descritiva e comparada para estudar os normativos internacionais e outros instrumentos internacionais. Vale enfatizar que temos em consideração a perspectiva de gênero no presente artigo, contemplando as variáveis de gênero e Tráfico de pessoas e os estereótipos de gêneros (papéis atribuídos a homens e a mulheres por razoes socioculturais) que são favorecedores da desigualdade, da dominação patriarcal e favorece a prostituição e o tráfico de mulheres.

\section{Algumas precisões conceituais sobre - Tráfico de Pessoas e Trabalho forçado}

Inicialmente, apresentamos os conceitos internacionalmente aceitados para 
Tráfico de pessoas e para trabalho forçado com o objetivo de deixar claro que estamos diante de duas instituições jurídicas distintas para o direito internacional. Sem prejuízo, de que o Tráfico de pessoas também pode apresentar os elementos de trabalho forçado. Para ressaltar esta sinergia negativa entre esta forma de exploração do trabalho e violação dos direitos humanos destacaremos os elementos constitutivos de cada um dos conceitos de modo a brindar uma devida claridade conceitual.

Primeiro deles, o conceito de Tráfico de pessoas é definido nos termos do Protocolo adicional à Convenção das Nações Unidas Contra o Crime Organizado Transnacional relativo à Prevenção, Repressão e Punição do Tráfico de pessoas, em especial Mulheres e Crianças de 2000 (Protocolo de Palermo), que em seu artigo 3 define:

a) A expressão "Tráfico de pessoas" significa $\bigcirc$ recrutamento, $\bigcirc$ transporte, a transferência, o alojamento ou o acolhimento de pessoas, recorrendo à ameaça ou uso da força ou a outras formas de coação, ao rapto, à fraude, ao engano, ao abuso de autoridade ou à situação de vulnerabilidade ou à entrega ou aceitação de pagamentos ou benefícios para obter o consentimento de uma pessoa que tenha autoridade sobre outra para fins de exploração. A exploração incluirá, no mínimo, a exploração da prostituição de outrem ou outras formas de exploração sexual, o trabalho ou serviços forçados, escravatura ou práticas similares à escravatura, a servidão ou a remoção de órgãos;

b) $O$ consentimento dado pela vítima de Tráfico de pessoas tendo em vista qualquer tipo de exploração descrito na alínea a) do presente Artigo será considerado irrelevante se tiver sido utilizado qualquer um dos meios referidos na alínea a);

c) $O$ recrutamento, o transporte, a transferência, o alojamento ou o acoIhimento de uma criança para fins de exploração serão considerados "Tráfico de pessoas" mesmo que não envolvam nenhum dos meios referidos da alínea a) do presente Artigo;

Conforme assevera a definição do Protocolo de Palermo o Tráfico de pessoas possui três elementos constitutivos: 1 . A ação que ocorre mediante o movimento (sendo o consentimento irrelevante); 2. Por meio de coação, engano, ou violência; 3. Com o fim de exploração do trabalho alheio (grifo nosso).

Já o trabalho forçado é definido internacionalmente mediante o Convênio $N^{\circ} 29$ sobre trabalho forçado ou obrigatório da Organização Internacional do Trabalho (OIT), que define o trabalho forçado ou obrigatório como aquele que "[...] designa todo trabalho ou serviço exigido a um indivíduo sob a ameaça de uma pena qualquer e, para o qual, o dito indivíduo não tenha se oferecido voluntariamente." (OIT, 1932, art. 2.1). Para a OIT "La amenaza de una pena incluye amenazas de violencia física contra un trabajador - sus familiares, confinamiento físico y negación de derecho"(OIT, 2005, p. 5). Deste modo, podemos observar que possui dois elementos constitutivos: 1. "trabaIho ou serviço exigido a um indivíduo sob a ameaça de uma pena qualquer"; 2. "para o qual este indivíduo não se ofereceu voluntariamente" (grifo nosso). Para Jordan, o trabalho forçado geralmente ocorre mediante uma falsa promessa de emprego, na qual ilude a suposta vítima com um trabalho em boas condições $e$ remunerações, que logo não são cumpridas. Além de, em muitos casos, nem serem remunerados, também são submetidas a 
violência física e psicológica, e ainda sofrem restrições de liberdade e movimento (JORDAN, 2011, p. 5), configurando com isso o trabalho forçado.

Apresentados os conceitos e elementos constitutivos do Tráfico de pessoas e do trabalho forçado passamos agora para um segundo momento, no qual apresentaremos como se configura o trabalho forçado no tráfico de mulheres com fins de exploração sexual.

\section{Sinergias negativas: $O$ Trabalho forçado no Tráfico de mulheres com fins de exploração sexual}

O tráfico de mulheres para fins de exploração consiste na utilização de mulheres no comércio sexual, que dentre outros aspectos, contempla, serviços sexuais, indústria do sexo, pornografia, turismo sexual, espetáculos sexuais ou atividades similares. Neste contexto, 0 traficante se beneficia dos lucros da exploração sexual alheia. Conforme colocamos em evidência através da definição internacionalmente aceitada, que deriva do Protocolo de Palermo, o consentimento da vítima é irrelevante, já que os meios usados (coação e/ou engano, uso da força ou violência) com um determinado fim, caracterizam o delito, e a pessoa sujeita ao mesmo, será a vítima.

Segundo dados do Informe Global sobre - Tráfico de pessoas da ONU 2009 a prostituição é a atividade final mais enfatizada dentro do tráfico para fins sexuais comerciais. A prostituição é a atividade a que se dedica quem mantém relações sexuais com outras pessoas, em troca de dinheiro. Acompanhando as leis do mercado, no contexto do Tráfico, fazemos referência a um comércio onde existe uma oferta e uma demanda. Em mencionado comércio, o cliente é um ator chave, já que é o sujeito que promove os fundos econômicos que sustentam esta atividade. Dentro da demanda, também incluímos os proxenetas, dado que são os responsáveis por captar as vítimas sob engano, ademais de coagirem às vitimas a manterem a atividade sexual, e obterem benefícios econômicos da exploração do trabalho alheio. Por outro lado, temos a vítima, que é a pessoa que tem vulnerados seus direitos humanos.

Observamos que a lógica da exploração no tráfico geralmente ocorre mediante o trabalho forçado. Que de acordo com a Organização Internacional do Trabalho (OIT) este, "generalmente será desarrollado mediante condiciones de trabajo inferiores a las normas establecidas por la ley" (OIT, 2001, pgf. 146), o que acomete em aspectos que supõe o trabaIho forçado (idem, pgf. 141). Em geral, o trabalho forçado resultante no Tráfico de pessoas, costuma comprometer as pessoas que se encontram em situação administrativa irregular, ou as que trabalham na economia submergida. Ao mesmo tempo, a OIT adverte:

\begin{abstract}
"La trata de personas resulta a veces bastante compleja y requiere un examen uno sólo de la manera en que un migrante haya entrado en el país, sino también de sus condiciones de trabajo y de si el migrante ha consentido en la entrada clandestina $y / o$ en esas condiciones de trabajo (...) Los tratantes manipulan a la persona para sacar dinero del trabajo forzoso al que acaban obligándola." (ibídem, pgf. 145).
\end{abstract}

Ainda que os conceitos de Tráfico de pessoas e de trabalho forçado estejam interconectados, como evidenciamos são conceitos diferentes de acordo com o Direito internacional, embora, na prática, suscite grande confusão. Apesar de ambos conterem componentes de trabalho forçado, 
não estamos diante de instituições jurídicas idênticas e sim, inter-relacionadas. Por isso, se faz necessário ter presente o conceito de trabalho forçado, de modo a possibilitar uma orientação para a cooperação entre os países e tendo como objetivo o cumprimento das convenções N.29 e N.105 da OIT, bem como o respeito de direitos e princípios que favoreçam a compreensão do que se entende por exploração. Deste modo, a utilização do conceito de trabalho forçado e o componente de exploração, podem ajudar a análise de distintos contextos de Tráfico de pessoas e concomitantemente uma aproximação mais ampla das situações de abuso e violência em que se encontram submetidos os trabalhadores, especialmente aqueles explorados sexualmente. De acordo com - "Grupo de trabalho contra o Tráfico de pessoas" da ONU,

"La noción de explotación laboral en la definición de la trata de personas permite establecer un vínculo entre el Protocolo contra la trata de personas y el Convenio de la OIT, relativo al trabajo forzoso u obligatorio y deja claro que en la definición de trabajo forzoso u obligatorio que contiene el Convenio se abarca la trata de personas con fines de explotación."(ONU: CTOC/ COP/WG.4, 2010, pgf. 13)

Quando uma pessoa está submetida a um trabalho contra sua vontade, sob ameaça de violência ou qualquer forma de coação ou castigo, se encontra restringida sua liberdade, além de exercer sobre ela os atributos do direito de propriedade ou alguns desses; fato que se contempla desde o Tráfico de pessoas e sua exploração mediante trabalho forçado, como forma contemporânea de escravidão.

De acordo com a definição estabelecida pelo Convênio N. 29 (1930) pela OIT, ob- servamos que essa contém duas características principais: Primeiro - $O$ trabalho é exigido mediante a ameaça de uma pena; Segundo - O trabalho é realizado de forma involuntária (OIT, 2005, pgf. 14). Destarte o Tráfico de pessoas com fins de exploração sexual é, portanto uma tipologia do trabalho forçado. Neste sentido, a OIT identifica seis elementos substanciais que podem evidenciar circunstâncias de trabalho forçado relacionados com o Tráfico: 1. Ameaça de violência física ou sexual - neste contexto pode também incluir a violência psicológica, a chantagem, tortura emocional, linguagem vexatório e degradante-; 2. Restrição de movimentos do trabalhador/a a uma zona limitada ou reclusão no lugar de trabalho; 3. Condição análoga à escravidão, servidão por dívidas - "Se da cuando una persona pasa a ser la garantía o fianza de un préstamo -"; 4. Retenção dos salários ou negativa em pagar ao trabalhador; 5 . Confiscação de passaportes e documentos de identidade; 6. Ameaça de denúncia às autoridades das trabalhadoras e dos trabalhadores migrantes em situação administrativa irregular (OIT, 2006, pp. 20-21).

O considerar a presença desses componentes, as consequências da imigração, desde o trabalho forçado, supomos que a coação ocorre indiretamente, em virtude da imigração "clandestina" em um país, e por isso as vítimas se mostram receadas em denunciar o trabalho forçado já que se encontram em situação administrativa irregular e são constantemente coagidas pelo explorador que the recordando que cometeram um ilícito contra o Estado.

Ademais, a Declaração da OIT sobre os princípios e direitos fundamentais no trabalho, agrupa o trabalho da OIT no enfrentamento ao Tráfico de pessoas e para benefício dos direitos dos trabalhadores, por meio de quatro princípios: Primeiro - Eliminação de todas as formas de trabalho forçado ou obrigatório; 
Segundo - Abolição efetiva do trabalho infantil; Terceiro - Eliminação da discriminação em matéria de emprego e ocupação; Quarto - Liberdade de associação e sindical e reconhecimento efetivo do direito de negociação coletiva.

A grande maioria das vítimas de tráfico com fins de exploração sexual se encontram em situação de trabalho forçado, seja por aceitar um trabalho no exterior, sem conhecer as condições reais de trabalho, ou por se comprometerem com uma dívida inicial com o traficante que a levou ao lugar de destino onde se encontra explorada, ou ainda, porque exerce um trabalho sob "ameaça". Diante deste contexto a OIT chama a atenção para o fato de que:

\begin{abstract}
"En algunos países es muy corriente que las migrantes soliciten un IVisado para espectáculosil. Estos visados son desde hace varios años blanco de muchas críticas porque sirven de cobertura legal a la trata de mujeres con fines de explotación sexual. [...] Otro método habitual de reclutamiento con fines de explotación sexual es la publicación de anuncios en los que los traficantes fingen ser amigos o parientes, o bien agencias matrimoniales." (OIT, 2005, pgf. 244)
\end{abstract}

De acordo com o informe de 2009, apresentado pelo Escritório das Nações Unidas sobre Drogas e Crime (UNODC), o tráfico com fins de exploração sexual é mais facilmente detectado por três motivos (UNODC, 2009, p.51): Primeiro - Devido a própria legislação, já que os Estados, em sua grande maioria, tipificaram o tráfico com fins de exploração sexual, não fazendo menção a sua relação com fins de exploração laboral; Segundo - A relação direta que restringe o tráfico somente aos fins de exploração sexual; Terceiro. Pela facilidade e detectar o trá- fico com fins de exploração sexual frente ao laboral. $O$ comércio sexual geralmente circunscreve espaço público para atrair aos possíveis clientes, e por isso, é mais visível; enquanto que exploração laboral geralmente ocorre em fábricas clandestinas, no serviço doméstico ou em "enclaves étnicos" de difícil visibilidade.

Diante dessa realidade de ausência de proteção efetiva, a OIT corrobora que:

"El escaso grado de cumplimiento de la legislación puede atribuirse a la ausencia de mecanismos de protección de las víctimas, así como al desconocimiento de lo que realmente son el trabajo forzoso y la trata entre las autoridades encargadas del cumplimiento de las leyes y del poder judicial. Las autoridades no siempre dan una interpretación uniforme a su propia legislación, sobre todo cuanto se trata de distinguir entre las leyes sobre la inmigración (en las que suele preverse la expulsión inmediata de los trabajadores inmigrados en situación irregular) y aquellas por las que se tutelan los derechos humanos y laborales $y$, más concretamente, los derechos fundamentales de las víctimas de trata." (OIT,2005, pgf. 277)

Assim sendo, para que seja alcançada a proteção a todas as vítimas de Tráfico de pessoas, se considera fundamental o cumprimento efetivo do Direito internacional aplicável sobre a matéria, ou seja: "O direito a não ser submetido a trabalhos forçados constitui um dos valores democráticos da sociedade que não permite restrição de nenhum tipo". Não obstante, se faz importante relacionar o Tráfico de pessoas ao trabalho forçado, a servidão por dívidas e/ou a escravidão já que a ausência desta relação propicia um enfoque enganoso e restrito destas formas 
contemporâneas de escravidão que geralmente se encontram em constante sinergia negativa.

\section{Considerações Finais}

Como buscamos evidenciar estamos diante de dois conceitos diferentes e com elementos constitutivos próprios dentro do escopo do direito internacional público, não obstante se faz visível a sinergia existente na exploração do trabalho (forçado) na ação de tráfico de pessoas. Diante de tais asseverações, entendemos que o Tráfico de pessoas é um componente da estrutura de exploração do trabalho no atual mercado que tem suas bases na divisão social de trabalho, na falta de oportunidades, na dificuldade do acesso ao mesmo, nas desigualdades de poder fundadas no gênero, na discriminação e na estigmatização de algumas ocupações. Como consequência, dessas bases poderia alcançar uma forma mais efetiva de enfrentar o Tráfico de pessoas, que deve passar inevitavelmente pela promoção e pela proteção dos direitos dos trabalhadores, contra qualquer tipo de trabalho forçado e/ou obrigatório, para assim conseguir ações que protejam com maior firmeza os direitos humanos. Neste ínterim se faz imperativo o estabelecimento "sinestésico" entre o respeito as normas de proteção aos direitos humanos bem assim correlacionar o respeito às leis laborais, com vistas a garantir o trabalho digno na construção de uma sociedade que dilacera e usurpa a dignidade do ser humano por via de formas contemporâneas de escravidão.

\section{REFERÊNCIAS}

BRASIL. Decreto $n^{\circ}$ 5017, de 12 de março de 2004. Promulga o Protocolo Adicional à Convenção das Nações Unidas contra o Crime Organizado
Transnacional Relativo à Prevenção, Repressão e Punição do Tráfico de pessoas, em Especial Mulheres e Crianças.

CAUCHO, Lydia. Esclavas del Poder. Un Viaje al corazón de la trata sexual de mujeres y niñas en el mundo. Ed. Debate. Barcelona, 2010.

CCEM. Actes du colloque. Esclavage moderne et trafic d'êtres humains, quelles approches européennes? Paris : Comité Contre l'esclavage Moderne/ Centre de Conférences Internationales. 17 de novembre 2000.

CORREA DA SILVA, Waldimeiry. Formas Contemporaneas de Esclavitud : Trata de Mujeres. Sevilla, España. Tesis doctoral. Universidad de Sevilla, $2011,481 \mathrm{p}$.

DECAUX, E. Les Formes contemporaines de l'esclavage. Recueil des Cours: Collected courses of the Hague Academy of International Law. Leiden/Boston: Martinus Niihoff Publishers, 2009. (Tome 336)

JORDAN, A. La esclavitud, el trabajo forzado, la servidumbre por deudas, y la trata de personas : de la confusion conceptual a de soluciones acertadas. Center For Human Rights \& Humanitarin Law. Documento de Discusión 2. Febrero 2011 . Disponível em: <http://rightswork.org/wp-content/uploads/2011/09/Documento-de-Discusion-2.pdf $>$ acesso em: 25/04/2012.

MOLINA, M.L. Explotación sexual. Evaluación y tratamiento. Buenos Aires : Ed. Dunken, 2008.

ORGANIZAÇÃO INTERNACIONAL DO TRABALHO. Convención $N^{\circ} 29$ sobre trabajo forzoso $U$ obligatorio de la OIT. Adoptado en la Conferencia General de la Organización Internacional del Trabajo (sesión 14). Convenio relativo al trabajo forzoso u obligatorio, del 28 de junio de 1930, Ginebra.

.Convención $N^{\circ} 105$ de la OIT sobre la Abolición del Trabajo Forzoso de 1957. Adoptado en la Conferencia General de la Organización Internacional del Trabajen (sesión 40), 25 de junio de 1957, en Ginebra.

. Declaración de la OIT relativa a los Principios y Derechos fundamentales en el trabajo. Conferencia Internacional del Trabajo, $86^{\circ}$ reunión, Ginebra, junio de 1998.

OIT, 2001.

.Alto al trabajo forzoso. Ginebra: 
.Una alianza Global contra el trabajo forzoso. Ginebra: OIT, 2005.

Trata de seres humanos y trabajo forzoso como forma de explotación. Guía sobre la legislación y su aplicación. Ginebra: OIT, 2006.

Tráfico de pessoas para fins de exploração sexual. Brasília: OIT, 2006.

.Trabalho Forçado e Tráfico de pessoas. Um Manual para inspectores do trabalho. Dirigido por Beate Andreez. Genebra: OIT, 2008.

El costo de la coacción. Informe global con arreglo al seguimiento de la Declaración de la OIT relativa a los principios y derechos fundamentales en el trabajo Conferencia Internacional del Trabajo, 98. ${ }^{a}$ reunión. Ginebra: OIT, 2009.

ORGANIZAÇÃO DAS NAÇÕES UNIDAS. Análisis de algunos conceptos básicos del Protocolo contra la Trata de Personas. Doc: CTOC/COP/ WG.4/2010/2, de 9 de dezembro de 2009.
SOUSA SANTOS, B. Crítica da Razão Indolente. Contra o desperdício da experiência. São Paulo: Cortez, 2000.

UNODC. Global Report on Trafficking in Persons: Human Trafficking a crime that shames us all. New York/Ginebra: UN.GIFT (Global Initiative to Fight Human Trafficking), 2009.

UNODC. Informe Mundial sobre la Trata de personas (Resumen ejecutivo). New York: ONU, 2009.

UNODC. Ley modelo contra la trata de personas. Viena/Nueva York: UNOCD, 2010

VAZ CABRAL, G. La traite des êtres humains: Realités de l'esclavage contemporain. La Découverte. Paris, 2006. 